\title{
SEMPREVIVA E MULAS COMO CONSTRUCTO DE UM ESPAÇO TRANSCULTURAL E TRANSNACIONAL
}

\author{
Sempreviva and Mulas as a construct of a transcultural and transnational space
}

Sempreviva y Mulas como construcción de un espacio transcultural y transnacional

Lucilene Machado Garcia Arf ${ }^{*}$

Professora Adjunta do curso de Letras/CPAN e no Programa de Mestrado em Estudos Fronteiriços.
Mestra em Estudos Literários/UFMS e doutora em Teoria da Literatura/UNESP -
lucilenemachado@terra.com.br

Recebido em 09/04/2020. Aceito para publicação em 10/04/2020

Versão online publicada em 05/05/2020 (http://seer.ufrgs.br/paraonde)

\begin{abstract}
Resumo:
A leitura do texto literário aponta para a necessidade de um olhar crítico e profundo sobre as fronteiras, uma vez que a mobilidade cultural revela a construção de um espaço transcultural e transnacional diferenciado. Com este estudo, buscamos um olhar mais atento à produção literocultural da fronteira oeste de Mato Grosso do Sul, enfatizando a necessidade de abarcar os conceitos de transculturalidade e transnacionalidade para compreender a narratividade da existência humana, bem como vislumbrar novas perspectivas interpretativas. Utilizamos como objeto de investigação as obras Mulas, de Luiz Taques e Sempreviva de Antonio Callado e para referenciar esse trabalho, buscamos o pensamento de Homi Bhabha como o principal aporte teórico para reflexões a respeito dos princípios da formação identitária, comportamentos, impasses e avanços na fronteira. Usamos ainda Ítalo Calvino, entre outros, para falar de literatura e sociedade e a necessidade desta no constructo da memória.
\end{abstract}

Palavras-chave: Literatura. Fronteira. Transculturalidade. Transnacionalidade. Espaço.

\begin{abstract}
:
The reading of a literary text appoints to a needing of a deep and critic look about the frontier, once that a cultural movability reveals the construction of a transcultural and transnational space different. In this study, we search more carefully look to a production cultural-literature of the frontier in west on Mato Grosso do Sul, emphasizing the needing to look on the concept of the transculturation and transnationality to comprehend the narrativity of the human existence, and catch a glimpse of new perspectives interpretative. We used like objective of investigation the books Mula from Luiz Taques and Sempreviva from Antonio Callado and to refer this article, we researched the thought from Homi Bhabha like a principal teoric contribution to reflections about principles of identifying formation, behaviors, impasses and advances in frontier. We also used Ítalo Calvino, and others, to talk about literature and society and the needing of that in construct of the memory.
\end{abstract}

Key-words: Literature. Frontier. Transculturation. Transnationality. Space.

\section{Resumen:}

La lectura del texto literario señala la necesidad de una mirada crítica y profundizada sobre las fronteras, ya que la movilidad cultural revela la construcción de un espacio trancultural y transnacional diferenciados. Con este estudio, intentamos un examen 
más atento a la producción litero cultural de la frontera oeste de Mato Grosso do Sul, dando énfasis a la necesidad de abarcar los conceptos de tranculruralidad y transnacionalidad para comprender la narratividad de la existencia humana, como también vislumbrar nuevas perspectivas interpretativas. Utilizamos como objeto de investigación las obras Mulas de Luiz Taques y Sempreviva de Antonio Callado y para referenciar nuestra investigación, empleamos el pensamiento de Homi Bhabha como el principal aporte teórico para reflexiones a respecto de los principios de formación identitaria, comportamientos, impases y avances en la frontera. Usamos todavía Italo Calvino, entre otros, para discutir literatura y sociedad y la necesidad de ésta en la construcción de la memoria.

Palabras-clave: Literatura. Frontera. Transculturalidad. Transnacionalidad. Espacio.

\title{
1. O espaço fronteiriço em mato Grosso do Sul
}

O espaço é um elemento importante na estrutura de uma narrativa, seja ela curta ou longa. Toda história assume um espaço real ou imaginário que é desenhado no discurso da fala. Paisagens, cidades, efeitos urbanos são objetos de atenção em leituras científicas e produzem interessantes encontros multidisciplinares entre geografia, história, história da arte, literatura ou Teorias da literatura, linguística e outras áreas do conhecimento que debatem essa questão. Mas, além disso, nossa proposta é falar de um espaço que tenta identificar valores e conceitos de indivíduos que vivem nos limites fronteiriços das nações. São pessoas que vivem em dois sistemas de pensamento, com várias línguas, diferentes leis e diferentes consciências.

Essa é a realidade da fronteira entre o Brasil e a Bolívia, especialmente nas cidades de Corumbá e Ladário, no Mato Grosso do Sul e nas cidades bolivianas de Puerto Quijarro e Puerto Suarez, onde é possível observar o fluxo de pessoas circulando em ambos os lados, em uma interação orientada por uma variedade de circunstâncias que envolvem economia, política, cultura, religião, entre outras.

A transculturalidade e a transnacionalidade são objetos de muitos estudos nessa faixa de fronteira, onde a identidade e os valores que caracterizam a população são bastante singulares, atraindo grande interesse dos pesquisadores. O que vamos discutir, no entanto, é sobre a produção literocultural, especialmente as narrativas que foram produzidas em ou sobre este lugar e como seus personagens, que mimetizam a vida fronteiriça, são afetados pelos costumes locais. De acordo com Wolfgang Iser,

\begin{abstract}
Los seres humanos están tan enredados en su entorno, tan formados e condicionados por lo que prolongan de sí mismos, y tan desafiados por el mismo hábitat que construyeron para sobrevivir y mantenerse, que de manera inevitable el interés en la cultura surge en proporción al declive de una opinión uniforme de la naturaleza humana. (ISER, 2005, p. 178)
\end{abstract}

A literatura expõe esses sujeitos arraigados aos seus espaços, pressupõe muitos tipos de discursos contemporâneos ou anteriores, diferentes formas de expressão de uma sociedade, bem como suas diferentes linguagens, sejam elas positivas ou negativas. É quase impossível pensar em

ParaOnde!?, Porto Alegre, v.13, n.2, p.207-217, 2020.http://seer.ufrgs.br/paraonde Edição Especial - VII Seminário Internacional de Estudos Fronteriços 
construção sociocultural sem a ajuda da literatura. O que também constitui um desafio para as ciências sociais e estudos históricos que utilizam esse aporte em suas especificidades.

Para o brasileiro Gabriel Perissé (2006), a literatura não é uma fuga da realidade, mas sim para a realidade e atua como uma ferramenta metodológica para desenvolver ações integradoras com o fim de uma aproximação cultural. A literatura de determinados lugares é um meio relevante de interação entre as pessoas e a realidade, especialmente quando o eixo se atem a elementos do quadro humano, de fatores culturais e históricos. Dessa maneira, a obra fronteiriça é pensada como um legado enriquecedor da identidade da população local, além de fazer parte do panorama literário nacional. As fronteiras se constituem em espaços humanos, onde comunidades com características particulares, marcadas pela interculturalidade, são naturalmente integradas e, como produto do encontro, surge a cultura criada e recriada por seus habitantes.

Este produto é transformado em uma fonte de conhecimento, identidade, valores que seriam de grande interesse para a política governamental, com o fim de integração e desenvolvimento, porém, muitas vezes eles são desconsiderados. Segundo Homi Bhabha,

\footnotetext{
Esses entre-lugares fornecem 0 terreno para elaboração de estratégias de subjetivação - singular ou coletiva - que dão início a novos signos de identidade e postos inovadores de colaboração e contestação, no ato de definir a própria ideia de sociedade. (BHABHA, 2007, p. 20)
}

No lado brasileiro deste propício terreno, temos escritores como Manoel de Barros, Lobivar Matos, Abílio de Barros, Augusto César Proença, Luiz Taques, Antonio Callado, entre outros, que estão ou estiveram especificamente circunscritos neste local. Os povos fronteiriços, como participantes desse território dotados de paradoxos e complexidades, são sujeitos imanentes e objetos de uma série de narrativas sociais e locais. Além disso, a denominação fronteira esconde um território onde as memórias e as recordações de ontem são caminhos poucos percorridos, são lembranças esquecidas que não conhecem o presente e, da mesma forma, não conhecerão o futuro. Há uma falta de validadores para as histórias imaginárias capazes de reconhecer os elementos do tempo e do espaço. Falta a arte de narrar, a arte de recontar e, se essa arte não cumpre o seu papel, se perdem as histórias. Por sua vez, as experiências escritas excedem o tempo, além de tornar o leitor cúmplice de suas ficções e espaços propostos. Vale atentar para o que disse Italo Calvino (2009, p. 342) em Assunto encerrado: discursos sobre literatura e sociedade quando alerta para o fato dos escritores não ocuparem as próprias posições. Para ele, "a literatura não pode deixar lugares vazios sem que eles venham a ser ocupados: no pior dos casos, pelos maus escritores e, no melhor, por escritores de tipo tradicional. "

Temos na parte sul do estado do Mato Grosso do Sul, a fronteira com o Paraguai, cuja produção literária atingiu um importante processo se relacionado à chamada pós-modernidade, recebendo, inclusive, a atenção de

ParaOnde!?, Porto Alegre, v.13, n.2, p.207-217, 2020.http://seer.ufrgs.br/paraonde Edição Especial - VII Seminário Internacional de Estudos Fronteriços 
pesquisadores de várias partes do país e de importantes instituições, entretanto, a fronteira oeste não teve o mesmo desenvolvimento. Por outro lado, é possível perceber que ela está passando por um processo de transformação, que começa a viver um cenário notável de produção, o que a converte, finalmente, em um território de pertencimento, identidade e enunciação. Pouco a pouco, podemos avançar por esse amplo trilho, orientando-nos por reflexões que nos permitem deslindar diferentes interesses, de modo que o não-lugar de uma identidade denegada e sem valor aparente se torne outro, porém agora de pertencimento e erradicação, reafirmando-se no reconhecimento de sua própria singularidade.

Historicamente, o espaço fronteiriço ocidental é mais antigo que o sul, mas com menos tempo de efervescência humana, já que o lado boliviano era desabitado, enquanto o sul, embora mais recente, tinha sua urbanização e população mais rápidas. A fronteira oeste do estado sempre foi um lugar mais distante da cultura da guerra, mas a barbárie sempre esteve presente. No caso do processo literário, a escassa produção do espaço sempre se ateve à natureza e à cidade de Corumbá, que no século XIX teve um desenvolvimento valorizado dentro da nação brasileira pelo papel que desdobrava nas navegações.

\section{Mulas espaço de cultura e enunciação}

A literatura é empregada como uma das ferramentas para melhor compreender a mudança que se enuncia, pois pode ser pensada como um lugar de múltiplas histórias, saberes e falas, lugares de cultura e enunciação, já que todo texto literário é um espaço discursivo no qual aflora os registros das diversas práticas e pertencimentos culturais de uma determinada região, e que, portanto, devemos considerar a região como elemento constitutivo do discurso do texto literário, onde se abarcam as vozes e registros de uma geografia regional. Para Calvino,

É a literatura (...) o campo de energias que apoia e motiva esse encontro e confronto da pesquisa e operações em disciplinas diferentes, ainda que aparentemente distantes ou estranhas. É a literatura como espaço de significados e de formas que valem não só para a literatura. Nós acreditamos que as poéticas literárias podem remeter a uma poética do fazer, aliás: do fazer-se. (CALVINO, 2009, p. 315)

Seguindo intuitivamente estas recomendações, Luiz Taques, em seu livro Mulas, coloca em cena a imagem de uma fronteira que tende a se repetir, ainda que codificada força intente suplantar seus malefícios e ocultar parte dos acontecimentos. Taques recorre à fronteira Corumbá / Puerto Suarez, na década de 70, onde, de fato, viveu alguns anos de sua vida e onde retornou várias vezes, sempre com um olhar ficcionista que tenta fazer do espaço fronteiriço um local para seus personagens. Em seu livro, Taques insiste em uma fronteira injusta, pobre, sem instrução e inclusive bárbara, quando os acontecimentos se dão longe da capital do estado e ainda mais longe dos

ParaOnde!?, Porto Alegre, v.13, n.2, p.207-217, 2020.http://seer.ufrgs.br/paraonde Edição Especial - VII Seminário Internacional de Estudos Fronteriços 
centros brasileiros. O que, em termos de Angel Rama, sobre a "Ciudad letrada", é onde se disseminam os valores da civilização e que os anéis protetores das grandes culturas não chegam a proteger as periferias, ou seja, para ele, a maior distância entre a região central expõe o grau de civilização e vice-versa.

Taques acentua esses anéis invisíveis e apresenta os atores que fazem essa fronteira: polícia, bandidos, chefes de trânsito:

\begin{abstract}
A bolivianinha foi forçada a transar, inúmeras vezes, com alguns dos encarregados pela lei na fronteira. Alternando-se. Trepada compulsória. Sem libido. Não adiantava espernear. Dar chilique. Gritar. Não iriam escutá-la. (...) ou tentar correr. Sempre haveria alguém na espreita. A dar cobertura. $\mathrm{Na}$ fronteira oeste brasileira, vigorava o pacto: alguém sempre haveria de dar cobertura. (TAQUES, 2019, p. 45)
\end{abstract}

A obra apresenta um jogo de forças, acentuando-se o grupo dominante sobre o grupo dominado. Terry Eagleton (2005) em A ideia da cultura, trata das formas efetivas de poder como uma persuasão moral, uma maneira pela qual uma ordem governante molda, para si mesma, uma identidade (p. 83). Ou o poder da cultura dominante é ironicamente abalizar uma visão idealista de si mesma. A personagem de nacionalidade boliviana, cujo nome é o diminutivo da palavra "boliviana", sofre uma dominação constante, em graus crescentes, que demonstra um padrão exemplar do grupo dominador. Embora seja uma relação marcada pela indiferença e pela violência, demarca um campo de referências dentro das relações fronteiriças. Não se pode falar sobre identidades sem falar sobre relacionamentos, já que não pode falar sobre relacionamentos sem falar sobre os papéis sociais. $O$ contato entre os indivíduos estabelece uma relação de injunção mútua, que ultrapassa o círculo da individualidade. É um contato assimétrico, mas que produz hierarquias de acordo com seu grau de legitimidade. Um processo de valores e pontos de vista se desencadeiam bilateralmente transportando significações que vão sendo internalizadas em diferentes proporções.

As identidades são postas em oposições, revelando-se uma a outra, tendo seus traços caraterísticos evidenciados. O conjunto de estereótipos de cada identidade encerra e determina o modo de ser de seus portadores como um referencial e estabelece uma situação econômica, política e social díspares, além de tomadas preconceituosas que persistem, mesmo com a passagem de aproximadamente 40 anos:

Mesmo com pouca experiência na comarca fronteiriça, o magistrado já ouvira falar que o boliviano apreciava mastigar folha de coca ou beber o chá feito com folha de coca; e que apenas uma minoria (os abastados, aqueles que viviam na opulência) cheirava pó. (2018, p. 56)

Observamos, no discurso de Taques, o grupo discriminado por sua alteridade, representado, no caso, pela "bolivianinha", sendo manipulado e reproduzindo o padrão do dominador que não deixa de repudiar a moça e tratála como objeto sem muita importância. Na conclusão do livro, passam a dividir

ParaOnde!?, Porto Alegre, v.13, n.2, p.207-217, 2020.http://seer.ufrgs.br/paraonde Edição Especial - VII Seminário Internacional de Estudos Fronteriços 
a cela do presídio local: uma brasileira, que figura na obra como uma personagem secundária, e a Bolivianinha que é ofendida, injuriada, vilipendiada e destroçada em sua condição de boliviana, mulher e pobre:

E então, com um olhar carregado de ódio, a Ribeirinha avançara sobre a companheira de cela. Quando as agentes penitenciárias, alertadas pela gritaria infernal, conseguiram chegar nelas, tirar a viúva daquele jovem pai de gêmeos de cima, dominá-la, algemá-la, a Bolivianinha de Puerto Suárez, devido aos golpes de estilete que atingiram sua barriga e pescoço, não passava de um cadáver magrelo, encharcado de sangue, deitado em posição fetal. (TAQUES, 2019, p. 86)

Taques desenha o espaço fronteiriço geograficamente estabelecido entre Brasil e Bolívia, porém este transcende à questão física e se manifesta como um lugar onde duas ou mais culturas diferentes se entrelaçam. É um cruzamento diário que resulta no que chamou Homi Bhaba de "terceiro espaço", uma combinação de espaço, de poder e domínio que criam um lugar simbólico e intelectual que não é físico, é onde se organizam as condições de enunciação que põe em interdito a estabilidade dos símbolos da cultura pois estes são "re-historizados e re-lidos" (Bhaba 2002, p. 58). Mas o que se interroga não é simplesmente a imagem dessa mulher como um cadáver, mas - lugar discursivo onde as questões de identidades são estratégicas e institucionalmente colocadas num microcosmos que a ade da identidade é a presença angustiada dentro do "eu", de uma agonia fronteiriça que emerge quando se olha perigosamente pelo buraco da fechadura de uma cela.

Assim, a fronteira entre Corumbá e Puerto Quijarro é um lugar que reúne condições que se "re-historizam" e se legitimam como um espaço que permite os sujeitos que fazem suas travessias a se apropriarem de valores que se mesclam em sua conjugação de mundos. A visão de Taques se desenvolve em um terreno literário, no entanto, é uma narrativa mimética e realista. Mover o enquadramento do campo de visão para o espaço da escrita, põe em questão uma dimensão mais profunda da representatividade do "eu" e o "outro", é como se ignorasse a forma, a estética e criasse uma dimensão vertical dentro dos significados. É uma verticalidade significativa, não pela violência dos fatos, mas pela luz que projeta nas relações cotidianas dos habitantes fronteiriços, no registro da semelhança e da analogia. São relações por meio das quais se percebe e se representa o espaço e o tempo da cultura em sua região. Podese chamar de um sistema simbólico e legítimo onde se conforma uma ética própria.

\section{Sempreviva: fronteira, contradições e fusões}

A outra obra selecionada para este estudo tem também a moldura da barbárie inscrita no espaço fronteiriço, com uma variante a mais. Embora sejam histórias que circulam no mesmo espaço de tempo, a obra Sempreviva de Antonio Callado, publicada em 1981, tem o agravante da disputa política ditatorial ocorrida no Brasil. Callado escolhe a fronteira entre o Brasil e a Bolívia

ParaOnde!?, Porto Alegre, v.13, n.2, p.207-217, 2020.http://seer.ufrgs.br/paraonde Edição Especial - VII Seminário Internacional de Estudos Fronteriços 
para criar uma narrativa que combina realismo e ficção. Como assinala Iser ( $p$. 318) "A narrativa funciona como uma forma de comunicação que se esforça para dotar a especulação filosófica com credibilidade". O discurso de Callado retrata situações que poderiam ser reais e ter semelhanças com eventos históricos, político-sociais brasileiros. Há uma narração paralela que trata das situações romanescas passíveis de serem interpretadas, de acordo com os sentidos acumulados, uma vez que os territórios Brasil / Bolívia estão envolvidos e todo simbolismo que possam representar. O livro começa com uma frase que já enuncia sinais de uma área de fronteira:

\begin{abstract}
Ainda em terra boliviana, rolando sem sono na cama da pensão de Puerto Suárez, Quinho viu e sentiu o Brasil ali pertinho, como de fato estava, na esquina, por assim dizer, calculou mesmo os míseros dois quilômetros, se tanto, que o separavam do portão da fronteira, que ia atravessar a pé, ou de automóvel, se preferisse, e ao rever e recapitular, no leito calorento, o portão, já mais de uma vez contemplado. (CALLADO, 1981, p.13)
\end{abstract}

Sempreviva é, em suma, a história de Vasco Soares, o protagonista de apelido Quinho, sob o disfarce de um membro de uma sociedade internacional para a proteção da vida selvagem e é responsável por informar sobre o caçador de onças Antero Varjão - nova identidade do ex-policial e torturador Claudemiro Marques - e sua fazenda "La Pantanera" também chamada de "Onça sem roupa" localizada na cidade de Corumbá, no Mato Grosso do Sul. Entretanto, a verdadeira motivação é descobrir onde Corina e Verónica, duas guerrilhas provavelmente mortas pelo ex-policial, poderiam estar enterradas. Com a ajuda de Jupira Iriarte, com quem Quinho estabelece uma relação afetiva, especialmente por ela apresentar semelhanças com Lucinda, sua grande paixão, morta pelas forças da repressão, ele empreende a missão de desvendar os fatos históricos e políticos. Quinho é responsável pela morte de Antero, usando a estratégia de embebê-lo no sangue da onça, animal típico do pantanal comumente mortos em caçadas, o que instiga os cães da fazenda a destroçá-lo. Depois de cumprir o que fora a sua missão: descobrir os corpos no pântano e se vingar de suas mortes, Quinho se prepara para sair de Corumbá com Jupira, mas é notificado por uma carta, chegada de Londres, da verdadeira identidade de Juvenal Palhano, amigo de Jupira. Na verdade, ele é o médico legista Ari Knut que, junto com Claudemiro, matara Lucinda, no porão da tortura. Quando Quinho tenta se vingar, já o encontra morto pela mordida da cobra Joselina, bicho de estimação de Herinha, filha de Jupira. Em seguida, Quinho, imediatamente, é morto pelos partidários de Antero que estavam sob o comando de Ari Knut.

O romance de Callado é denso, é composto por muitos personagens e vários núcleos. A obra delineia o contorno da fronteira oeste do estado do Mato Grosso do Sul, e perfaz uma ideia do mundo que ali passa a existir. É a periferia e a visão do país em seus extremos. Callado faz o oposto de Taques ao criar seus personagens de origem brasileira e colocá-los a viver em terras bolivianas: "Não ia ficar na Bolívia, esperando que voltasse não, falou Lucinda, não ia ficar dias no suarento Puerto Suárez, na pensão, sem saber o que se passava, não ia aguardar, fora de cena, sua própria libertação." (1981, p.14)

ParaOnde!?, Porto Alegre, v.13, n.2, p.207-217, 2020.http://seer.ufrgs.br/paraonde Edição Especial - VII Seminário Internacional de Estudos Fronteriços 
Espaço e literatura encontram na descrição uma variedade de formas às quais 0 autor recorre para representar os aspectos gerais ou pormenorizados do que quer mostrar por meio da palavra escrita, situando o leitor, tanto espacial quanto temporariamente, na obra.

A cidade é detalhada em suas dimensões, em suas desolações e como literatura fronteiriça fica uma sensação de que há muito para dizer, que a luz da teoria literária tem muito a iluminar e que estamos diante de um livro que é um épico dos acontecimentos que levaram ao surgimento da democracia na América do Sul. É uma literatura de pioneiros, de pessoas que fazem coisas pela primeira vez, que as escrevem como criação original, explorando espaços que estão diante de nossos olhos, mas que nunca vimos nos espaços dos livros, é um poder encontrar-se, talvez cruzar nossas próprias fronteiras. É quando nos deparamos com a poética que narra as características geográficas de seu lugar, as determinações climáticas, os intercâmbios sócio-políticos, econômicos e culturais, os fluxos migratórios e as relações entre os dois países e seus resultados, embora suas concentrações urbanas sejam muito recentes.

$\mathrm{Na}$ construção dos personagens, Callado também aborda o cotidiano, o que faz, por exemplo, quando apresenta o personagem Pepe:

\begin{abstract}
Postado à mesa diante de uma garrafa de vinho, Pepe - tristes bigodões de salgueiro de beira-rio, de guias tão compridas e cadentes que pareciam mirar, com certa intencionalidade, os canos das botas que o boliviano calçava - começou logo a falar, como se não tivesse interrompido a conversa da véspera, macia, emoliente, destinada a convencê-lo de que passar a fronteira era para ele, Quinho, nada mais do que a visita, a volta à casa paterna, o abrir da velha cancela, do portão de outrora, familiar, acolhedor. (CALLADO, 1981p. 16)
\end{abstract}

Callado se baseia nas múltiplas expressões geradas a partir de um olhar sobre a gente fronteiriça, apontando seus gostos e os processos que enfrentam como lógica de vida, junto à necessidade de construção de sentidos que é o que conforma a identidade que parece atada aos problemas de organização individual e social. As noções de sujeito que se organizam em duplo eixo: pessoal e de estado, onde se articula o processo de constituição do sujeito para o qual se examina o papel da vida cotidiana e do espaço público para essa construção, culminando com a relação entre identidade e ideologia.

O imaginário da cidade recriado pelos textos literários pode ser considerado um mapa que nos aproxima da compreensão de nossa complexa fronteira. É um esboço para o qual não se pretende dar uma imagem definitiva e sim conscientizar de uma realidade que resiste a ser entendida de forma unívoca, porque a fronteira oeste está marcada por contradições e fusões onde se misturam e se integram termos para enriquecer-se, mas também são inevitáveis as rupturas. Os dois autores se ocupam com a vida cotidiana das cidades fronteiriças, abordando temas centrais de suas problemáticas, mas não se deixam cair no grotesco ou no sensacionalismo. As cidades de Puerto Suárez e Corumbá são constituídas como o espaço onde as histórias acontecem. Cidades reinventadas e multifacetadas, capazes de serem cruéis, dolorosas, desumanas, sufocantes, mas também acolhedoras e hospitaleiras.

ParaOnde!?, Porto Alegre, v.13, n.2, p.207-217, 2020.http://seer.ufrgs.br/paraonde Edição Especial - VII Seminário Internacional de Estudos Fronteriços 
São reveladas não apenas como realidades urbanas e motivos para a escrita, mas também como uma reestruturação da consciência político-social.

As imagens das regiões fronteiriças albergam uma multiplicidade de significados, bem como o que ouvimos falar sobre o pragmatismo de seus habitantes, mas nada alcança explicar tudo. O estigma de um lugar de passagem, prostíbulo, antro de criminosos e traficantes de drogas, ou como um lugar ideal ao converter-se na porta de entrada para imigrantes que sonham com uma nova vida. Porém, são apenas algumas das afirmações usadas na tentativa de descrever a fronteira. Embora seja factível encontrar argumentos fundamentados a favor ou contra que respaldem toda especulação a propósito dessas afirmações, não devemos ser reducionistas, tampouco eliminar nenhuma delas. Todas essas declarações têm algo a dizer sobre a fronteira. É possível encontrar asseverações, suposições, deduções ou mesmo tentativas baseadas em teorias que dizem respeito a fronteiras, mas o que tento afirmar é que a região de fronteira permite a coexistência de opiniões diversas, o que não cabe são os discursos totalizantes. A fronteira é apresentada como um conceito sujeito a constantes mudanças e movimentos, o que a torna atraente e desprezível, desejada e rejeitada.

\begin{abstract}
Vamos atravessar juntos a fronteira do Brasil, para Corumbá, nada mais fácil, afinal de contas, ainda mais que imagino que você está sentindo, tanto quanto eu, a força da voragem, não está, o sopro para dentro que daqui a pouco faz esta cama furar a parede do quarto, o muro da casa, o portão da barreira militar, e nós, como numa bandeja, em cima do lençol, na nudez, copulantes, presas fáceis, incapazes de qualquer gesto de defesa ou orgulhosos demais para isso, voltando à pátria que nos fodeu, no auge e glória de uma foda. (CALLADO, 1981, p. 15)
\end{abstract}

A parede, o muro, o portão como barreiras entre os dois países transforma-se no processo de interação simbólica, o que separa serve como elementos para se construir um elo de ligação, um movimento temporal diante da passagem que pode propiciar. O presente dos personagens é incerto no aquém da fronteira, mas é prometedor de um futuro além das margens. As fronteiras de casa e do mundo se confundem e o privado e o público, estranhamente, tornam-se parte um parte do outro.

Na mesma linha, parece essencial também viajar pelo campo cultural e literário nos perguntando quais são os critérios para o estudo da literatura a partir de uma perspectiva regional, uma vez que as cidades do interior do país deixaram de ser sinônimo de atraso social e adquiriram maior destaque, equivalentes em alguns casos a nível nacional, considerando que uma literatura de determinada região pode ser reconhecida pela relação entre o escritor, o que ele escreve e o lugar onde vive, convocando os leitores a considerar os condicionamentos históricos e sociais e o desenvolvimento da literatura. Bhabha assinala que "como criaturas literárias e animais políticos, devemos nos preocupar com a compreensão da ação humana e do mundo social como um momento em que algo está fora de controle, mas não fora da possibilidade de organização." (2007, p. 34)

ParaOnde!?, Porto Alegre, v.13, n.2, p.207-217, 2020.http://seer.ufrgs.br/paraonde Edição Especial - VII Seminário Internacional de Estudos Fronteriços 


\section{4. À GUISA DE CONCLUSÃO}

As duas obras, tomadas em conjunto, defendem certa "civilidade" contra as formas de barbarismo, que os valores culturais não são os de qualquer forma de vida particular, mas, simplesmente, da vida humana como tal. Essa cultura pode ser universal, mas precisa de um espaço para prosperar, um palco para se realizar, para assumir uma encarnação local. Taques fala da fronteira por um prisma singular representado pelo signo da sexualidade a partir de um olhar de voyeurismo do narrador que exibe as diferenças de poder, o jogo de estereótipos e as nacionalidades, partícipes do posicionamento sexual que mescla a lei e o desejo. Callado não vê diferenças culturais como fonte de conflito, mas como um interstício, um elemento espacial de conexão na criação de condições de sobrevivência. Constrói um movimento migrante de identificações sociais como pressupostos transparentes que dessacralizam a supremacia cultural, criando um espaço único de fronteira de posições minoritárias contra a ditadura perversa que atinge a todos.

Não podemos esquecer que a época datada pelos fatos é dos anos setenta, mas os acontecimentos remontam a situações muito similares à atualidade. O preconceito, a busca pelo poder, a violência, o cruzamento das linhas limites e o uso das línguas ainda seguem os mesmos padrões. Mas as cidades mudaram. Entre Puerto Suárez e Corumbá existe hoje outra cidade: Puerto Quijarro. O tecido social tem uma outra tessitura, embora o princípio transcultural segue o mesmo parâmetro. O transnacionalismo ficou mais evidente e os moradores parecem estar começando a olhar em seu próprio rosto, após anos de travessias às cegas. Houve um significativo período de urbanização na parte Boliviana, à força de interesses particulares e coletivos e alargou-se a consciência da complexidade da sociedade.

Quanto à produção de literatura na fronteira oeste, é dada ao escritor a possibilidade de ocupar os espaços vazios, de garantir a sobrevivência dos discursos humanos. A narrativa, a poesia e a crítica adquirem um peso especial na medida em que dão vozes àqueles que estão sem voz. Para Calvino (2009, p. 344 e 345 ) A literatura é um instrumento de autoconsciência de uma sociedade, um instrumento essencial porque suas origens estão vinculadas às origens de diversos tipos de conhecimentos, de vários códigos, de várias formas do 'pensamento crítico. Para ele, a literatura é necessária à política quando, entre outras coisas, dá nome àquilo que não tem nome, especialmente àquilo que a linguagem política quer excluir. A literatura é como um ouvido que pode escutar além da linguagem que a política entende, é como um olho que pode ver além da escada cromática que a política percebe. Ao escritor, pode ocorrer de explorar regiões que ninguém explorou antes, dentro de si ou fora, fazer descobertas que cedo ou tarde resultarão em campos essenciais para consciência coletiva.

Que outros escritores exerçam na fronteira essa tarefa de observadorescritor, de não deixar nada ao acaso, de criar modelos de linguagem, de visão, imaginação, de trabalho mental, de correlação dos fatos, projeto estético,

ParaOnde!?, Porto Alegre, v.13, n.2, p.207-217, 2020.http://seer.ufrgs.br/paraonde Edição Especial - VII Seminário Internacional de Estudos Fronteriços 
ações em sociedade que são essenciais para verificar a vida acontecendo, a vida como ela é.

\section{Referências}

Bhabha, Homi K. El lugar de la cultura. César Aira (trad.). Buenos Aires: Manantial, 2002.

CALLADO, Antonio. Sempreviva. Rio de Janeiro: Nova Fronteira, 1981.

CALVINO, Ítalo. Assunto encerrado: discursos sobre literatura e sociedade. Trad. Roberta Barni. São Paulo: Companhia das Letras, 2009.

EAGLETON, Terry. A ideia de cultura. Trad. Sandra Castelo Branco. São Paulo: Editora Unesp, 2005.

ISER, Wolfgang. Rutas de la interpretación. Trad. Ricardo Rubio Ruiz. México: Fondo de Cultura Econômica, 2005.

PERISSÉ, Gabriel. Literatura e educação. Belo Horizonte: autêntica, 2006.

RAMA, Angel. La ciudad letrada. Montevideo: Arca, 1998.

TAQUES, Luiz. Mulas. Londrina: Kan, 2019. 